\title{
Effect of Frequency on Hydrocarbon (HC) Detection using 3D Finite Integral Modeling
}

\author{
Hanita Daud ${ }^{2, a}$, Majid Niaz Akhtar ${ }^{1, b}$, Noorhana Yahyaa,c, Nadeem Nasir ${ }^{1, d}$, \\ and Hasan Soleimani ${ }^{2, e}$
}

\author{
${ }^{1}$ Electrical and Electronics Engineering Department, \\ ${ }^{2}$ Fundamental and Applied Sciences Department, \\ Universiti Teknologi PETRONAS, \\ Bandar Seri Iskandar, 31750 Tronoh, Perak, Malaysia
}

\begin{abstract}
ahanita_daud@petronas.com.my, ${ }^{b}$ majidniazakhtar@gmail.com, cnoorhana_yahya@petronas.com.my, dnadeemntu@hotmail.com, ehassan.soleimani@petronas.com.my
\end{abstract}

Keywords: Electromagnetic, Hydrocarbon, Sea Bed Logging, Antenna, CST

\begin{abstract}
Detection of hydrocarbon in sea bed logging (SBL) is still a very challenging task for deep target reservoirs. The response of electromagnetic (EM) field from marine environment is very low and it is very difficult to predict deep target reservoirs below $2500 \mathrm{~m}$ from the sea floor. Straight antennas at $0.125 \mathrm{~Hz}$ and $0.0625 \mathrm{~Hz}$ are used for the detection of deep target hydrocarbon reservoirs below the seafloor. The finite integration method (FIM) is applied on 3D geological seabed models. The proposed area of the seabed model $(16 \mathrm{~km} \times 16 \mathrm{~km})$ was simulated by using CST (computer simulation technology) EM studio. The comparison of different frequencies for different target depths was done in our proposed model. Total electric and magnetic fields were applied instead of scattered electric and magnetic fields, due to its accurate and precise measurements of resistivity contrast at the target depth up to $3000 \mathrm{~m}$. From the results, it was observed that straight antenna at $0.0625 \mathrm{~Hz}$ shows $50.11 \%$ resistivity contrast at target depth of $1000 \mathrm{~m}$ whereas straight antenna at $0.125 \mathrm{~Hz}$ showed $42.30 \%$ resistivity contrast at the same target depth for the E-field. It was found that the E-field response decreased as the target depth increased gradually by $500 \mathrm{~m}$ from $1000 \mathrm{~m}$ to $3000 \mathrm{~m}$ at different values of frequencies with constant current $(1250 \mathrm{~A})$. It was also investigated that at frequency of $0.0625 \mathrm{~Hz}$, straight antenna gave $7.10 \%$ better delineation of hydrocarbon at $3000 \mathrm{~m}$ target depth. It was speculated that an antenna at $0.0625 \mathrm{~Hz}$ may be able to detect hydrocarbon reservoirs at $4000 \mathrm{~m}$ target depth below the seafloor. This EM antenna may open a new frontier for oil and gas industry for the detection of deep target hydrocarbon reservoirs below the seafloor.
\end{abstract}

\section{Introduction}

Sea bed logging is an application of the control source electromagnetic method which is used to locate an oil reservoir beneath the sea floor by measuring electromagnetic fields [1-4]. In the typical control source method a horizontal electric dipole antenna is towed by a surface vessel at a short distance $30 \mathrm{~m}$ above from the sea floor [5-8]. The dipole antenna transmits very low frequency electromagnetic waves with frequency ranges from $0.25 \mathrm{~Hz}-10 \mathrm{~Hz}$ due to low frequency transmitted energy propagates down through the subsurface [9-12]. Low frequency electromagnetic waves attenuate more in the conductive layer and less in the resistance layer due to the skin depth. In a large resistive layer such as hydrocarbon electromagnetic energy flows along the reservoir (described as guided wave) is detected by the stationary sea floor electric or magnetic field detectors which are deployed on the sea floor. The control source electromagnetic method depends on the resistivity of the hydrocarbon and surrounding sediments. Hydrocarbon in the sea bed has a 
resistivity of few tens to hundred ohm meter (30 $\Omega \mathrm{m}-500 \Omega \mathrm{m})$, sea water $(0.5 \Omega \mathrm{m}-2 \Omega \mathrm{m})$ while all other layers including sediments in the sea have resistivity (1 $\Omega \mathrm{m}-2 \Omega \mathrm{m})$ [13-16]. In deep water the air wave effect is negligible so the wave guided back from the hydrocarbon can predict the presence of hydrocarbon [17]. Oil and gas industry usually is using $1250 \mathrm{~A}$ current and $0.125 \mathrm{~Hz}$ frequency to locate the oil below the sea floor. Deep target beyond $2.5 \mathrm{~km}$ from the sea floor the response from the hydrocarbon reservoir is very weak so that presence of hydrocarbon cannot be predicted. To overcome this problem, oil and gas industry is trying to decrease the frequency further in order to locate the hydrocarbon reservoir at target deep beyond $2.5 \mathrm{~km}[18,19]$. Straight antennas at $0.0625 \mathrm{~Hz}$ frequency are used with the same configurations as $0.125 \mathrm{~Hz}$ frequency to detect the hydrocarbon reservoir for deep targets. Computer simulation technology is used to simulate the sea bed environment. Maxwell's equations are used to solve any problem by discretizing each Maxwell's equations at low frequency to show the resistivity contrast. These Maxwell's grid equations are used as a code in the CST software. Maxwell's equations used in the CST software are given below.

$$
\begin{gathered}
\oint_{\partial A} \vec{E} \cdot \overrightarrow{d s}=-\frac{\partial}{\partial t} \iint_{A} \vec{B} \cdot \overrightarrow{d A} \\
\oint_{\partial A} \vec{H} \cdot \overrightarrow{d s}=\iint_{A}\left[\frac{\partial D}{\partial t}+\vec{j}\right] \cdot \overrightarrow{d A} \\
\oiint_{\partial V} \vec{B} \cdot \overrightarrow{d A}=0 \\
\oiint_{\partial V} \vec{D} \cdot \overrightarrow{d A}=Q
\end{gathered}
$$

Propagation of electromagnetic (EM) waves travelling in seawater can be predicted by using Maxwell's equations. If the propagating of electromagnetic wave is in the z-direction then it can be described in terms of the electric field strength $E_{x}$ and the magnetic field strength $H_{y}$ [20].

$$
\begin{gathered}
E_{x}=E_{0} \exp ^{(j \omega t-\gamma z)} \\
H_{y}=H_{0} \exp ^{(j \omega t-\gamma z)} \\
\gamma=j \omega \sqrt{\varepsilon \mu-j \sigma \mu / \omega}=\alpha+j \beta
\end{gathered}
$$

Where $(\gamma)$ is the propagation constant, $(\varepsilon)$ is the permittivity, $(\mu)$ is the permeability, $(\sigma)$ is the conductivity, $\alpha$ is the attenuation factor, $\beta$ is the phase factor and $\omega=2 \pi \mathrm{f}$ is the angular frequency as given in Eq. (7). The electromagnetic wave propagation can be described by a wave number $K$ as given in Eq. (8):

$$
K=\omega \sqrt{\mu \omega+i \mu \sigma / \omega}=\frac{\omega}{c_{p}}+i / \delta
$$

Where $K$ is the wave number and $i=\sqrt{ }-1$ is the complex number, $c_{\mathrm{p}}$ is the phase velocity and $\delta$ is the skin depth. The first term in Eq. (8) inside the square root represents the displacement current and the second term represents the conduction current in the Maxwell's equation. Low frequency electromagnetic waves diffuse into the sea bed and attenuate in different resistive medium. The electromagnetic wave is guided along the high resistive layer and is attenuated less depending on the critical angle of incidence as reported in [18] and as shown in Fig. 1. Incident transmitted and reflected transverse electric field components of electromagnetic waves are given in Eqs. $(9,10)$. 


$$
\begin{aligned}
& E_{1^{\prime}}=\frac{\mu_{2} K_{1} \cos \theta_{1}-\mu_{1} K_{2} \cos \theta_{2}}{\mu_{2} K_{1} \cos \theta_{1}+\mu_{1} K_{2} \cos \theta_{2}} E_{1} \\
& E_{2}=\frac{2 \mu_{2} K_{1} \cos \theta_{1}}{\mu_{2} K_{1} \cos \theta_{1}+\mu_{1} K_{2} \cos \theta_{2}} E_{1}
\end{aligned}
$$

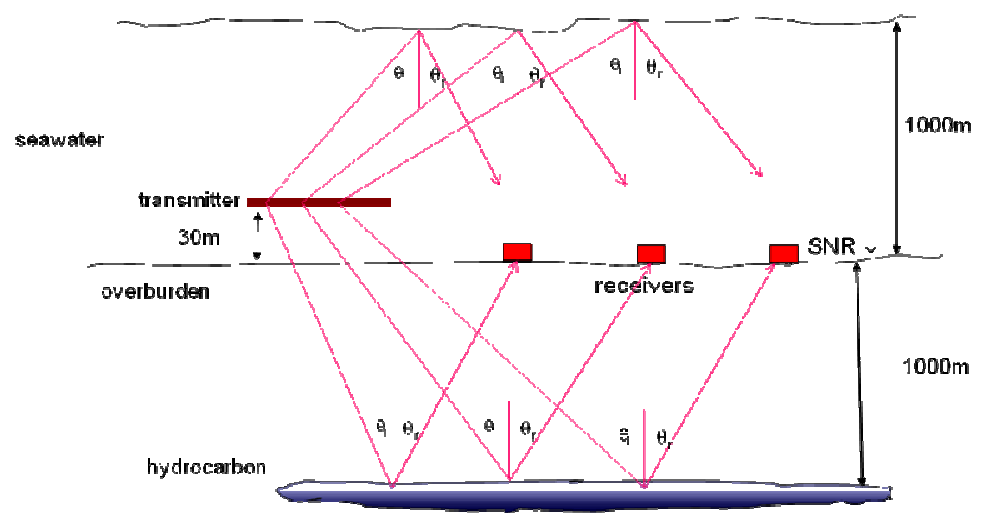

Fig. 1: Guided wave and reflected wave from sea water interface with hydrocarbon.

This work premise deals with the detection of hydrocarbon reservoirs below $2500 \mathrm{~m}$ target depth. Straight antenna at $0.0625 \mathrm{~Hz}$ was used to detect the deep target by using the computer simulation technology (CST) software with and without hydrocarbon and the results were compared with the straight antenna at $0.125 \mathrm{~Hz}$ frequency.

\section{Methodology}

The finite integration method (FIM) was used to detect the hydrocarbon reservoir with straight antenna at $0.125 \mathrm{~Hz}$ and $0.0625 \mathrm{~Hz}$ frequencies with same dimension as used in full scale by using the CST software. The proposed model with an area of $16 \mathrm{~km} \times 16 \mathrm{~km}$ was created in the CST software to replicate the full scale model. CST EM Studio was used to simulate the model with and without hydrocarbon. The first step was to set the antenna parameters such as length $(270 \mathrm{~m})$, frequency $(0.125 \mathrm{~Hz})$ and current $(1250 \mathrm{~A})$. Air thickness of $500 \mathrm{~m}$, sea water depth of $1000 \mathrm{~m}$, and hydrocarbon layer of $100 \mathrm{~m}$ was created to replicate full scale. Electric boundary conditions were applied. A low frequency full wave solver was run to simulate our proposed scale model. The final step was post processing to get the simulated data for analysis of results with and without hydrocarbon. The Maxwell's equations for magnetic and electric fields are used as a code in the software to get the electric and magnetic field response with and without hydrocarbon. A schematic diagram of the proposed model with antenna and receivers array on sea floor is shown in Fig. 2 . The proposed simulated parameters and resistivity contrast of different layers are given in Table 1 and Table 2 respectively. 


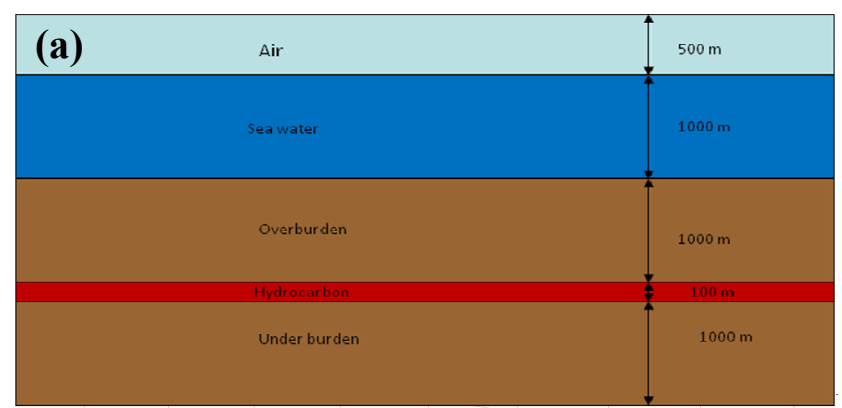

(b)

Fig 2: (a) Schematic diagram of proposed model and (b) CST simulated model.

Table 1. Simulated model parameters with different resistive layers (air, sea water, over burden and under burden)

\begin{tabular}{|l|l|l|l|l|l|}
\hline $\begin{array}{l}\text { Target } \\
\text { depth } \\
(\mathbf{m})\end{array}$ & $\begin{array}{l}\text { Air } \\
\text { Thickness } \\
(\mathbf{m})\end{array}$ & $\begin{array}{l}\text { Under } \\
\text { burden } \\
(\mathbf{m})\end{array}$ & $\begin{array}{l}\text { Hydro- } \\
\text {-carbon } \\
\text { thickness } \\
(\mathbf{m})\end{array}$ & $\begin{array}{l}\text { Sea } \\
\text { Water } \\
\text { depth }\end{array}$ & $\begin{array}{l}\text { Frequency } \\
(\mathbf{H z})\end{array}$ \\
\hline 1000 & 500 & 1000 & 100 & 1000 & 0.125 \\
\hline 1500 & 500 & 1000 & 100 & 1000 & 0.125 \\
\hline 2000 & 500 & 1000 & 100 & 1000 & 0.125 \\
\hline 2500 & 500 & 1000 & 100 & 1000 & 0.125 \\
\hline 1000 & 500 & 1000 & 100 & 1000 & 0.0625 \\
\hline 1500 & 500 & 1000 & 100 & 1000 & 0.0625 \\
\hline 2000 & 500 & 1000 & 100 & 1000 & 0.0625 \\
\hline 2500 & 500 & 1000 & 100 & 1000 & 0.0625 \\
\hline
\end{tabular}

Table 2. Relative permittivity, conductivity values of air, sea water Overburden/under burden and hydrocarbon

\begin{tabular}{|c|l|c|c|c|}
\hline $\begin{array}{l}\text { Permittivity } \\
\text { and } \\
\text { Conductivity } \\
\text { values }\end{array}$ & Air & $\begin{array}{l}\text { Sea } \\
\text { water }\end{array}$ & $\begin{array}{l}\text { Under } \\
\text { burden } \\
\text { /Overburden }\end{array}$ & Hydrocarbon \\
\hline$\varepsilon_{\mathrm{r}}$ & 1.006 & 81 & 30 & 4 \\
\hline$\sigma$ & $1.0 \mathrm{e}^{-11}$ & 4 & 1.5 & 0.001 \\
\hline
\end{tabular}




\section{Results and Discussion}

The magnitude versus offset response with and without the presence of hydrocarbon was investigated with a straight antenna at $0.0125 \mathrm{~Hz}$ and $0.0625 \mathrm{~Hz}$ frequency. The electric field response with the hydrocarbon reservoir is high compared to the magnetic field response so that is why the electric field response was included in this study. The effect of hydrocarbon reservoir at far offset shall be seen clearly when a log scale was used to plot the simulated data. At the peaks data was locked to see the difference at far offset with and without hydrocarbon.
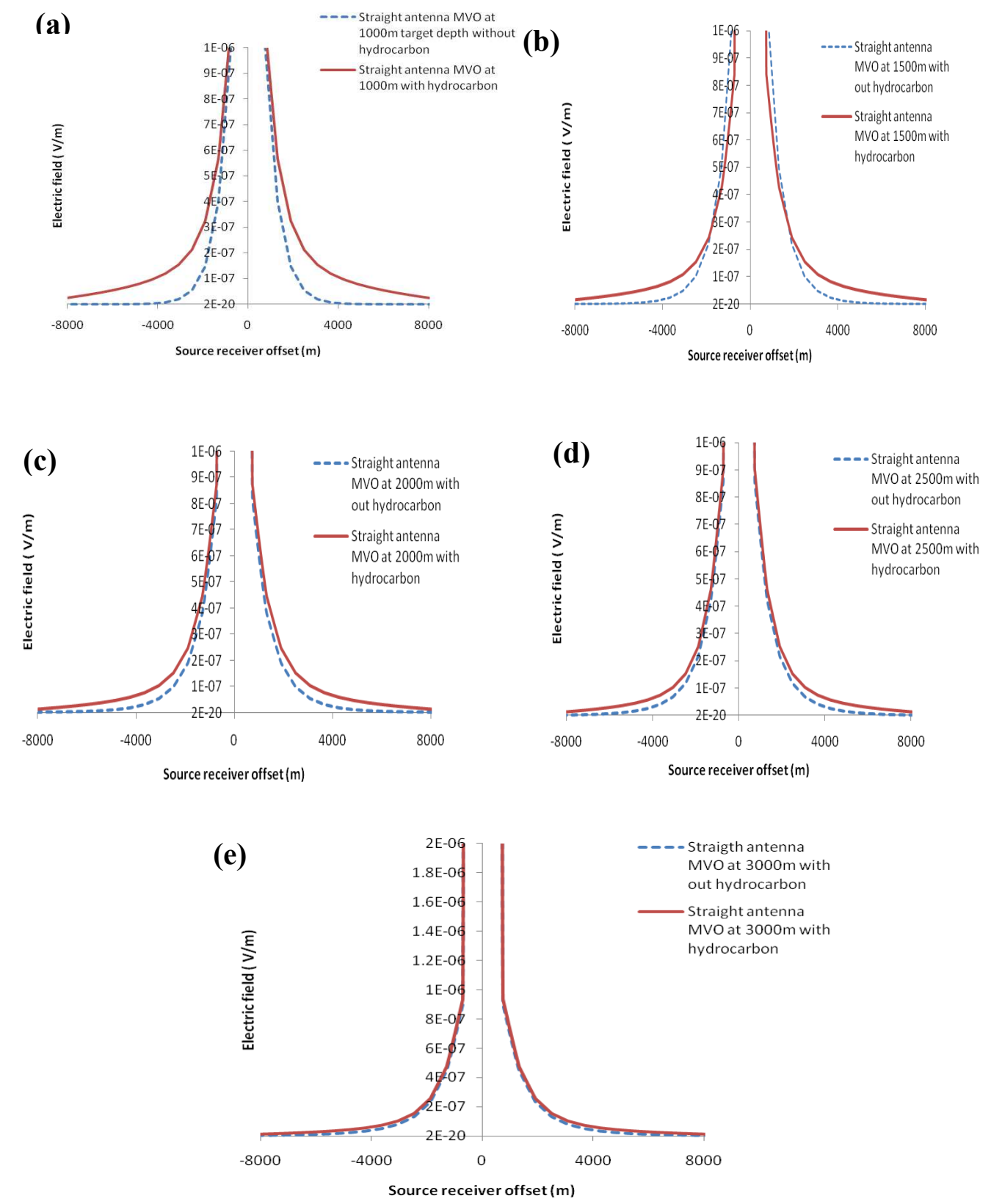

Fig 3: Straight antenna MVO with different target positions at $0.125 \mathrm{~Hz}$ frequency (a) $1000 \mathrm{~m}$ (b) $1500 \mathrm{~m}$ (c) $2000 \mathrm{~m}$ (d) $2500 \mathrm{~m}$ (e) $3000 \mathrm{~m}$.

Fig. 3 shows the electric field response from our proposed model which consists of a 1000 ohm-m resistive layer, $100 \mathrm{~m}$ thick covered with overburden and under burden layers of $1.5 \mathrm{~S} / \mathrm{m}$ conductivity. The total electric field response with and without hydrocarbon layers was taken instead of scattered electric field to get more precise results at different target depths. The solid line in Fig. 3 shows the hydrocarbon response of the electric field whereas the dash line indicates the 
response without hydrocarbon. At $1000 \mathrm{~m}$ target depth a straight antenna at $0.125 \mathrm{~Hz}$ frequency and 1250 A current shows $42.30 \%$ difference between with and without hydrocarbon as shown in Fig. 3a. As target depth increases from $1000 \mathrm{~m}$ to $1500 \mathrm{~m}$ below the sea floor the difference between with and without hydrocarbon decreases but still shows $19.94 \%$ difference. The target depth was varied from $1500 \mathrm{~m}$ to $2000 \mathrm{~m}$ and $2500 \mathrm{~m}$ below the sea floor and shows a percentage difference of $11.19 \%, 5.51 \%$ as shown in Fig. $3 \mathrm{c}$ and $3 \mathrm{~d}$, respectively. As the target depth increased the difference between the results with and without hydrocarbon decreased but at $2500 \mathrm{~m}$ it was still observed that a difference could be seen. At $3000 \mathrm{~m}$ target depth the response between with and without hydrocarbon is as shown in Fig. 3e. It was observed that the difference between with and without hydrocarbon cannot be seen clearly at this depth because the percentage difference is $1.24 \%$, i.e. too small to predict the presence of hydrocarbon. It was concluded that $1250 \mathrm{~A}$ current and $0.125 \mathrm{~Hz}$ frequency are not able to detect a target of more than $3000 \mathrm{~m}$. A decrease in the frequency is required or change the design of the antenna is needed.

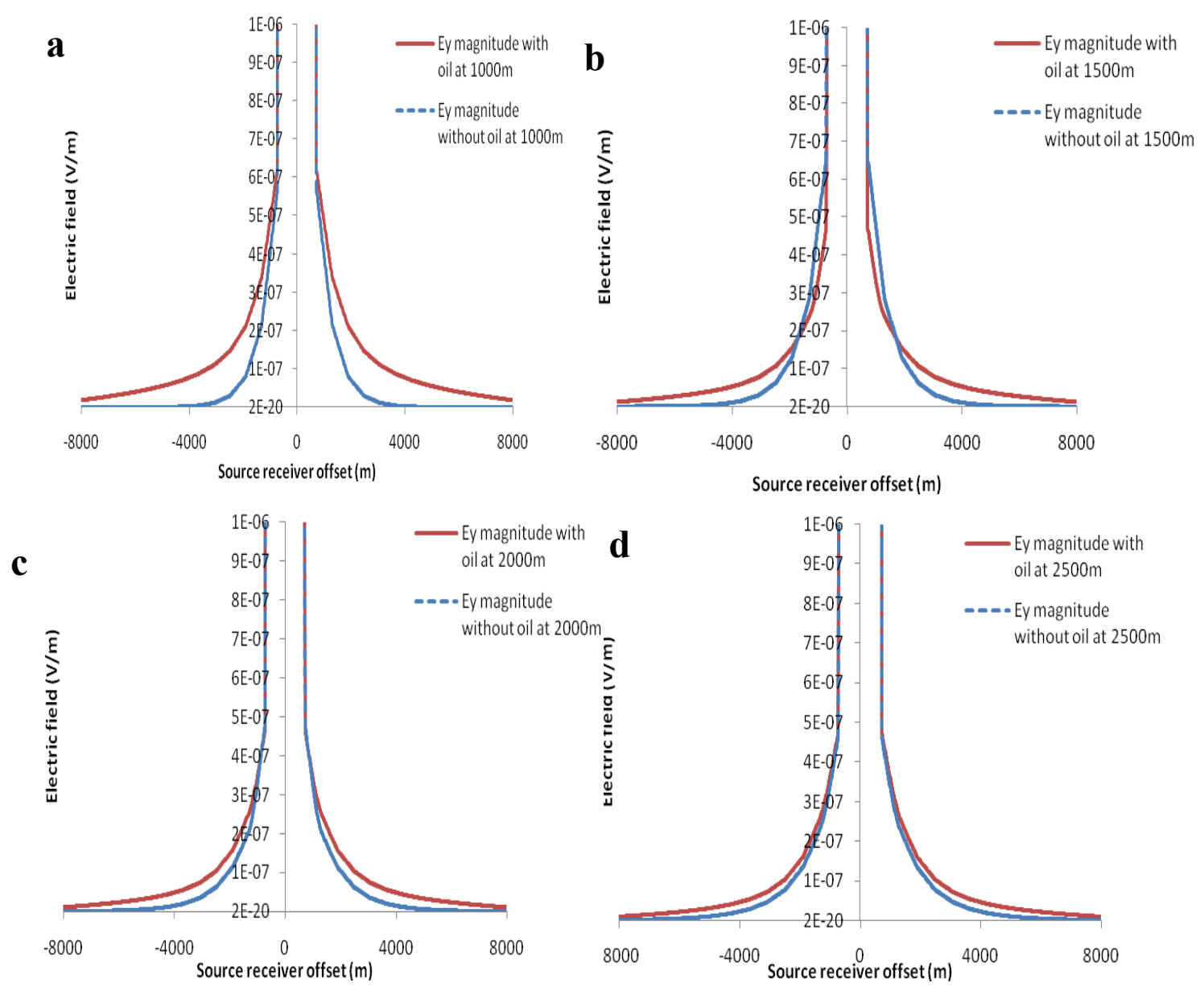




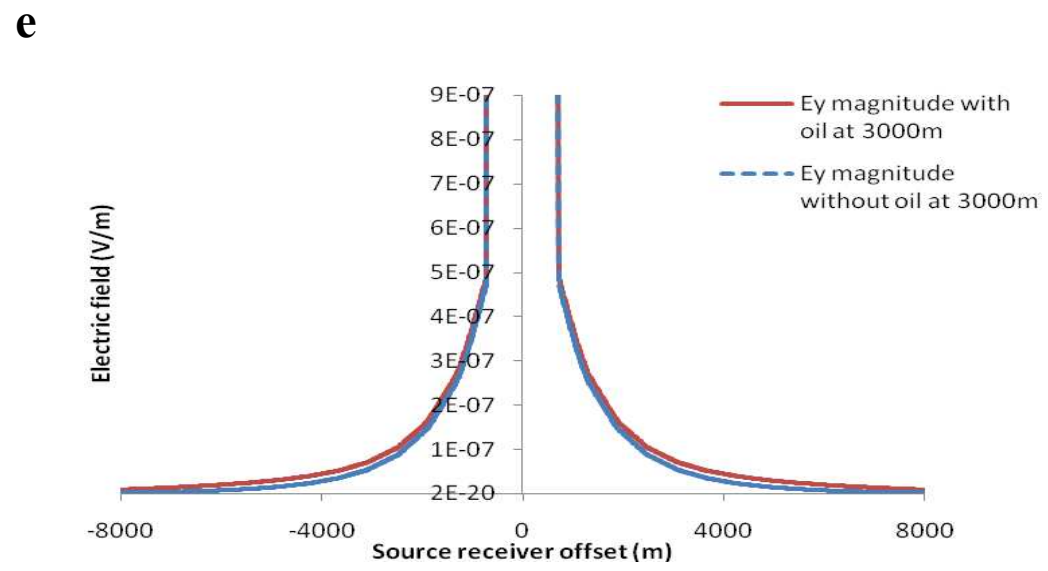

Fig 4: Straight antenna MVO with different target positions at $0.0625 \mathrm{~Hz}$ frequency (a) 1000

$$
\text { m (b) } 1500 \mathrm{~m} \text { (c) } 2000 \mathrm{~m} \text { (d) } 2500 \mathrm{~m} \text { (e) } 3000 \mathrm{~m} \text {. }
$$

A straight antenna at $0.0625 \mathrm{~Hz}$ was used in our proposed model to investigate the electric field response at different target depths. In this model the sea-air interface is also included to confirm that at $1000 \mathrm{~m}$ water depth air wave attenuates and has no effect on the data collected with and without hydrocarbon. The response from different target depths with straight antenna at $0.0625 \mathrm{~Hz}$ is as shown in Fig. 4. Figure 4 shows a clear difference of the straight antenna with $0.125 \mathrm{~Hz}$ frequency at $1000 \mathrm{~m}$ target depth. It was concluded that a straight antenna at $0.0625 \mathrm{~Hz}$ gave $50.11 \%$ electric field difference with and without hydrocarbon as shown in Fig. 4 (a) at $1000 \mathrm{~m}$ target depth. A straight antenna at $0.0625 \mathrm{~Hz}$ frequency at $1500 \mathrm{~m}, 2000 \mathrm{~m}$ and $2500 \mathrm{~m}$ target depth gave $27.48 \%$, $18.38 \%$ and $12.11 \%$ response of hydrocarbon respectively of a straight antenna at $0.0625 \mathrm{~Hz}$ frequency. As the target depth increases the electric field strength decreases. The target depth was increased from $2500 \mathrm{~m}$ to $3000 \mathrm{~m}$ to investigate the performance of a straight antenna at $0.0625 \mathrm{~Hz}$ frequency in detecting the hydrocarbon reservoir. It was observed that a straight antenna at 0.0625 $\mathrm{Hz}$ gave $7.10 \%$ higher electric field detection than a straight antenna at $3000 \mathrm{~m}$ target depth as shown in Fig. 4 (e). The percentage increase of the electric field response at different target depths with straight antenna at $0.125 \mathrm{~Hz}$ and $0.0625 \mathrm{~Hz}$ is shown in Table 3 .

Table 3. Percentage increase of electric field response with and without $\mathrm{HC}$ at different target depths

\begin{tabular}{|c|c|c|}
\hline $\begin{array}{c}\text { Target } \\
\text { Depth }(\mathrm{m})\end{array}$ & $\begin{array}{c}\% \text { difference in E field } \\
\text { with and without HC at } \\
0.125 \mathrm{~Hz} \text { frequency }\end{array}$ & $\begin{array}{c}\% \text { difference in E field } \\
\text { with and without HC at } \\
0.0625 \mathrm{~Hz} \text { frequency }\end{array}$ \\
\hline 1000 & 42.30 & 50.11 \\
\hline 1500 & 19.94 & 27.48 \\
\hline 2000 & 11.19 & 18.38 \\
\hline 2500 & 5.59 & 12.11 \\
\hline 3000 & 1.24 & 8.34 \\
\hline
\end{tabular}




\section{Conclusion}

EM modelling of our proposed model was done by FIM method. It was observed that the E-field response for a straight antenna at $0.0625 \mathrm{~Hz}$ shows $50.11 \%$ resistivity contrast at a target depth of $1000 \mathrm{~m}$ whereas a straight antenna showed $42.30 \%$ resistivity contrast at the same target depth. It was investigated that the E-field response decreased as the target depth increased gradually by 500 $\mathrm{m}$ from $1000 \mathrm{~m}$ to $3000 \mathrm{~m}$ at $0.125 \mathrm{~Hz}$ and $0.0625 \mathrm{~Hz}$ frequencies with a constant $1250 \mathrm{~A}$ current. It was also observed that at a frequency of $0.0625 \mathrm{~Hz}$ the straight antenna gave $7.10 \%$ better delineation of hydrocarbon at $3000 \mathrm{~m}$ target depth. It is speculated that this straight antenna at $0.0625 \mathrm{~Hz}$ can detect up to $4000 \mathrm{~m}$ target depth for better delineation of (HC) in seabed logging environment.

\section{References}

[1] L. MacGregor, and M. Sinha: Geophysical Prospecting Vol. 48 (2000), p. 1091-1106.

[2] B. Tossman, D. Thayer and W. Swartz: IEEE Journal of Oceanic Engineering Vol. 4 (1979), p. 84-89.

[3] S. Johansen et al.: First Break Vol. 23 (2005), p. 31-36.

[4] N. Yahya, M.N. Akhtar, N. Nasir, A. Shafie, M.S. Jabeli and K. Koziol: Article in Press, J. Nanosci. Nanotechnol. (2011).

[5] M.N. Akhtar, N. Yahya and N. Nasir: "New Al Em Transmitter with Yttrium Iron Garnet (Y3Fe5O12) Based Magnetic Feeders Potentially Used For Seabed Logging Application”, Nanosci tech, Shah Alam Selangor, Kuala Lampur (2011).

[6] N. Nasir, N. Yahya, M.N. Akhtar, M. Kashif, A. Shafie, H. Daud and H.M. Zaid: Journal of Applied Sciences 11 (2011), p. 1309-1314.

[7] M.N. Akhtar, N. Yahya, H. Daud, A. Shafie, H.M Zaid, M. Kashif and N. Nasir: Journal of Applied Sciences Vol. 11 (2011), p. 1361-1365.

[8] M. Unsworth: "New developments in conventional hydrocarbon exploration with electromagnetic methods," CSEG Recorder, (2005) p. 34-38.

[9] P. Clemmow: Proc. IEE Vol. 110 (1963), p. 101- 106.

[10] F.N. Kong, H. Weterdahl, S. Ellingsrud, T. Eidesmo and S. Johansen S: Oil and Gas Journal. Vol. 100 (2002), p. 30-38.

[11] C.S. Cox, S.C. Constable, A.D. Chave and S.C. Webb: Nature, vol. 320 (1986), p. $52-54$.

[12] M.C. Sinha, P.D. Patel, M.J. Unsworth, T.R.E. Owen and M.G.R. MacCormack: Marine Geophysical Research Vol. 12 (1990), p. 29-68.

[13] P.D. Young and C.S. Cox: Geophysical Research Letters, vol. 8 (1981), p.1043- 1046.

[14] E. Um and D. Alumbaugh: Geophysics Vol. 72 (2007).

[15] S.C. Webb, S.C. Constable, C.S. Cox and T.K. Deaton: J. Geomag. Geoele Vol. 37 (1985), p. $1115-1129$.

[16] A.D. Chave, S.C. Constable and R.N. Edwards: SEG, p. 931-966, (1982).

[17] T. Eidesmo,S. Ellingsrud, L.M. MacGregor, S.C.Constable, M.C. Sinha, S. Johansen, F.N. Kong, H. Westerdahl: First Break Vol. 20 (2002), p.144-152.

[18] S. Ellingsrud, T. Eidesmo, M.C. Sinha, L.M. MacGregor, S.C. Constable: Leading Edge, Vol. 20 (2002), p. 972-982.

[19] S. Ellingsrud, T. Eidesmo and K.M. Strack: SEG Las vegas annual meeting, Recent Advances and the Road ahead (2008).

[20] L.O. Loseth, H.M. Pedersen, B. Ursin, L. Admundsen and S. Ellingsrud: Geophysics, Res. Vol.71 (2006), p. $29-40$. 